\title{
EXPORTAÇÃO DE CACAU, CRESCIMENTO E DESENVOLVIMENTO REGIONAL NO SUL DA BAHIA (1965-1980)
}

\author{
Pedro Lopes Marinho ${ }^{1}$
}

\section{INTRODUÇÃO}

A partir de meados da década de 60 , quando o preço do cacau no mercado internacional subiu acentuadamente e alguns fatores internos mostravam-se favoráveis, esperava-se que a estratégia de promoção de exportação desse produto primário tivesse efeitos positivos no desenvolvimento regional, mesmo que não alcançando em nível nacional a repercussão de outros produtos, como por exemplo, o café e a soja.

Analisa-se neste trabalho o efeito das exportações de cacau para o crescimento e o desenvolvimento da região cacaueira da Bahia, no período de 1965 - 1980. A microrregião cacaueira da Bahia, definição do IBGE em 1967, com $18.102 \mathrm{Km}^{2}$, composta por 28 municípios, corresponde hoje à microrregião de Ilhéus e Itabuna, pela nova denominação do IBGE, com 41 municípios.

A análise será fundamentada no delineamento proposto por Schwartzman (1975) para uma estratégia de crescimento e desenvolvimento regional a partir de uma base de exportação. Para o autor se uma região consegue, apenas, consolidar sua base de exportação terá alcançado o crescimento regional, o desenvolvimento regional, porém, só se verificará se a região dinamizar e propagar sua base econômica.

Busca-se, então, evidenciar neste trabalho que em meados da década de 60 a região cacaueira da Bahia já teria consolidado sua base de

${ }^{1}$ Professor do departamento de Ciências Econômicas da Universidade Estadual de Santa Cruz - Ilhéus-Ba. Mestre em Desenvolvimento Econômico pela Universidade Federal do Paraná. 
exportação e consolidação verificada historicamente, mas que, apesar de alguns aspectos positivos, a região não conseguiu, entre 1965-1980, dinamizar e propagar sua base de exportação, não conseguindo desencadear efetivamente um processo de desenvolvimento regional a longo prazo.

\section{A TEORIA DA BASE DE EXPORTAÇÃO}

O artigo "Teoria da Localização e Crescimento Regional", de North (1955), é reconhecidamente o marco inicial da teoria da base de exportação. Apesar do conceito de base econômica ter sido empregado anteriormente por outros estudiosos, é North que dá a esse conceito o caráter de teoria do desenvolvimento regional.

Nesse artigo, North discorda de pensadores como E. M. Hoover e J. Fischer, que vêem o crescimento regional como seqüência dos estágios primário, secundário e terciário, que as regiões percorrem no curso de seu desenvolvimento e afirma: "Essa concepção não se aplica ao entendimento do crescimento das regiões dos Estados Unidos, o crescimento de uma região está intimamente vinculado ao sucesso de suas exportações" (NORTH, 1977, p. 297). Esse sucesso pode resultar na melhoria das exportações existentes em relação às áreas competitivas, ou como resultado do desenvolvimento de novas exportações.

No mesmo artigo, North evidencia ter-se inspirado nos insights de Harald Innis sobre o crescimento econômico canadense. As pesquisas de Innis convenceram-no da importância crucial dos produtos exportáveis primários na configuração das novas economias. O conceito empregado por Innis para designar o principal produto produzido pela indústria extrativa de uma região é produto primário e, em North, esse conceito é ampliado para produto de exportação de uma região, incluindo produtos primários, secundários e terciários. Ele usa a expressão produto de exportação ou serviço para se referir aos itens individuais e a expressão base de exportação para designar coletivamente os produtos de exportação de uma região. Reconhece o autor que se tratando de regiões novas, tipicamente baseadas na indústria extrativa, o seu conceito de produto de exportação é sinônimo do conceito de Export Staples de Innis. ${ }^{2}$

${ }^{2}$ Os estudos de Innis fundamentam a teoria Staples que, semelhante ao conceito da base de exportação, baseia-se no estudo sobre as características do produto de exportação e o exame das relações entre os fatores locacionais e o desenvolvimento regional. O conceito Staples, contudo, trata apenas de exportações primárias. 
$\mathrm{Na}$ teoria da base de exportação, as atividades econômicas de uma região se dividem entre as que são produzidas para o mercado exportador (atividades de exportação ou básicas) e as que são produzidas para o mercado interno (não básicas ou residenciais). O crescimento de uma região, segundo essa teoria, está vinculado à expansão de sua base de exportação. Essa expansão pode resultar: a) no crescimento da demanda do bem exportado pela região, devido a um aumento na renda na área do mercado, ou decorrente de mudança no gosto; b) no melhoramento dos custos de processamento ou de transferência (transporte) dos produtos de exportação da região em relação às regiões competidoras. Essa teoria centra-se na demanda agregada, tendo portanto um enfoque keynesiano. As exportações (produto básico) são o motor inicial do crescimento regional, crescimento esse determinado pelo multiplicador econômico regional. ${ }^{3}$

Tendo como referência a concepção de North, Schwartzman (1975) delineia o que poderiam ser os elementos para uma estratégia de crescimento e de desenvolvimento regional a partir de uma base de exportação.

\section{Crescimento regional}

Para desencadear o processo de crescimento a região tem de atender a demanda externa, tendo, portanto, que possuir o produto demandado, ${ }^{4}$ uma vez que os recursos estão desigualmente distribuídos entre as regiões. Não basta produzir o produto demandado por outra região nacional ou internacional. A região produtora terá de colocá-lo no mercado a preços competitivos. O preço do produto que a região terá de colocar no mercado dependerá dos seus custos de produção: a) custos de transferência, ou seja, os custos incorridos para trazer os insumos necessários até o local de produção e os custos de levar o produto até o consumidor; b) custo de processamento, ligado à fabricação do produto e que depende do estágio

$$
\begin{aligned}
& { }^{3} \mathrm{Y}=1 / 1-\mathrm{c}+\mathrm{m} / \mathrm{X} \\
& \mathrm{Y}=\text { nível de renda regional } \quad \mathrm{c}=\text { propensão a consumir da região } \\
& \mathrm{m}=\text { propensão a importar da região } \quad \mathrm{X}=\text { nível das exportações do }
\end{aligned}
$$

produto

${ }^{4}$ Em regiões novas e/ou subdesenvolvidas são geralmente os recursos naturais e algumas atividades primárias os produtos exportáveis e portanto indicadores do processo de crescimento e desenvolvimento. 
de desenvolvimento da região, o qual definirá o nível tecnológico para a produção, especialmente a relação capital/trabalho. ${ }^{5}$

\section{Desenvolvimento regional}

$\mathrm{O}$ atendimento à demanda externa e sua repercussão no nível de renda via multiplicador regional é insuficiente, por si só, para a compreensão do processo de desenvolvimento regional, e esse só será possível se a região for capaz de interiorizar e difundir as vantagens de sua base de exportação. Se o produto de exportação estiver apenas desenvolvendo-se sem atingir outros setores da economia, não se está diante de um verdadeiro processo de desenvolvimento. É necessário que outras atividades produtivas surjam, que a distribuição de renda atinja o maior número de pessoas e que, eventualmente, apareçam outras "bases" de exportação.

O dinamismo da base de exportação depende de fatores internos e externos: a) da elasticidade-renda da procura, isto é, se o produto (único) tem baixa elasticidade-renda não haverá uma tendência secular para o aumento de suas vendas, à medida que as regiões importadoras se desenvolvam; b) da capacidade de reduzir o custo de produção de exportação, seja pela melhoria da rede de transporte, seja por meio da melhoria na produtividade pela inovação tecnológica ou pelo maior e melhor uso do capital e de recursos humanos.

A difusão do dinamismo, contudo, dependerá dos seguintes aspectos: a) característica do produto de exportação, sendo que a tecnologia usada na produção pode causar repercussão em outros setores produtivos da região (encadeamento para trás - são as repercussões da indústria de exportação sobre outras atividades que podem fornecer-lhe insumos, inclusive bens de capital; encadeamento para frente - são os efeitos causados nas atividades que se criam para utilizar o produto da indústria de exportação; encadeamento da demanda final - refere-se ao investimento realizado na indústria local de bens de consumo para atender à procura dos fatores de produção da indústria de exportação e das outras atividades dependentes dela. Esse encadeamento dependerá do tamanho do mercado local e da distribuição de renda); b) diversidade dos recursos naturais da região, ou seja, se a região possuir outros recursos naturais de tal forma que o rendimento

${ }^{5}$ Dependendo da função de produção do bem exportado, a relação K/L (capital / trabalho) poderá ter influência na capacidade de uma região produzir competitivamente, por exemplo, se o bem exportado for de produção extensiva de capital e a relação $\mathrm{K} / \mathrm{L}$ for baixa. 
que eles possam oferecer não seja muito inferior ao da base de exportação e, então, com o desenvolvimento desses e o aparecimento de economias externas, eles poderão ser também explorados (diversificação); c) a maneira como a renda é distribuída.

\section{CONSOLIDAÇÃO DA BASE DE EXPORTAÇÃO CACAU}

\section{Custos de transferências}

A comercialização de cacau na Bahia compreende dois estágios: a) o primeiro estágio corresponde à comercialização interna, em que o cacau é transferido das fontes produtoras para os agentes exportadores; b) o segundo estágio é o da exportação efetivada pelas casas exportadoras visando ao mercado consumidor, na quase totalidade representado por países estrangeiros, no período analisado 1965-1980.

As dificuldades de transportes das áreas de produção, pela falta de estradas, constituíram um dos principais problemas da cacaicultura baiana, especialmente no primeiro ciclo de produção para exportação (1890 - 1931). Tal deficiência nos transportes para comercialização interna intensificou a presença da figura do intermediário entre o produtor e o exportador. $\mathrm{O}$ intermediário funcionava como atenuante desse problema, facilitando o escoamento da produção e abastecendo as propriedades rurais com gêneros diversos. Essa intermediação, porém, aumenta o custo de produção e reduz a parcela de lucro do produtor no produto. Inácio Tosta Filho, ${ }^{6}$ comentando sobre o problema dos transportes no primeiro ciclo da produção de cacau na Bahia para exportação, diz “...O transporte representa em certos lugares de 40 a $50 \%$ do valor do cacau nos portos primários de embarque" e conclui que o transporte para comercialização interna era precário para as necessidades de mais de $80 \%$ da produção de cacau antes de 1931 .

A criação do Instituto de Cacau da Bahia (ICB) em 1931 resolve o problema de transporte na comercialização interna do cacau. Entre os principais objetivos do Instituto, evidenciados no ato da sua criação, estava a solução para o problema do escoamento da produção interna. Num período de cinco anos (1931-1936), о Ісв havia concluído os trabalhos de locação e reconhecimento de uma razoável rede rodoviária na zona do cacau, constituída de $531 \mathrm{Km}$, da qual já tinha construído $290 \mathrm{Km}$ e reconstruído $82 \mathrm{Km}$ de antigas

${ }^{6}$ Citado por GARCEZ (1981, p. 14). 
rodovias interiormente quase que intrafegáveis como, por exemplo, a rodovia Ilhéus-Itabuna, ligando os dois principais centros urbanos da região. ${ }^{7}$

É sem dúvida excepcional o desempenho do ICB em relação ao problema do transporte. Em período relativamente curto, integra a região ao sistema viário do Estado da Bahia, assim como criou condições satisfatórias para o escoamento da safra, uma das questões mais urgentes da região. Cálculos de Inácio Tosta Filho (1960) evidenciam que a política do ICB, primordialmente voltada para o agricultor, especialmente no que diz respeito ao transporte, eleva o preço da mercadoria cacau na fazenda para cerca de $70 \%$ do valor $\mathrm{FOB}^{8}{ }^{8}$ já deduzidos os impostos municipais e estaduais, despesas de manutenção e outros. Para antes de 1931, o autor estipula, em média, 55\% a $60 \%$ desse valor.

\section{Custo de produção}

O estudo "Analisis Preliminar de los Costos de Producción de Cacao en Bahia en el años agricola 1965/6", do pesquisador da Comissão Executiva do Plano-Rural da Lavoura Cacaueira (CEPLAC) ${ }^{9}$ Richard Cox (1966), constitui o primeiro estudo importante sobre os custos da produção de cacau na economia cacaueira baiana. Apesar do período analisado, 1965/1966, esse estudo retrata, em verdade, a composição dos custos de produção de cacau na Bahia desde sua implantação, em solos baianos até o período analisado no trabalho, 1965/ 1966. Isso porque, ainda na década de 60, continuava-se a produzir cacau na Bahia como tinham produzido os pioneiros desbravadores. ${ }^{10}$

Analisando os custos de produção do cacau, Cox (1966) chega a algumas importantes conclusões: o principal fator que afeta o custo fixo total é o valor da terra, 64,08\% desse custo; na composição do custo variável, a mão-de-obra constitui o item principal, 70\% desse custo. Conclui ainda o autor que a relação entre o custo total unitário e o preço do produto é de $74 \%$, sendo o restante $26 \%$ o lucro bruto do produtor.

Essa forma extensiva de produzir cacau ganha força principalmente a partir do final do século XIX, quando o cacau passa a ser produto de

${ }^{7}$ Fonte: relatórios anuais do ICB, 1931-1936 citados por GARCEZ (1981).

${ }^{8}$ Significa que as importações e as exportações são computadas pelo valor de embarque, não incluindo os fretes e seguros.

${ }^{9}$ Hoje a CEPLAC significa Comissão Executiva do Plano da Lavoura Cacaueira.

${ }^{10}$ A forma de produzir cacau na Bahia só se alterará efetivamente na década de 70 com as técnicas "modernas" implantadas pela CEPLAC. 
destaque na pauta de exportação brasileira e vigora até a década de 70. A esse respeito, o próprio Cox, por referência, comenta: "Observa-se que na área estudada não se combatem pragas, não se controlam enfermidades, nem se usam fertilizantes" (cox, 1966, p. 10).

Sendo a mão-de-obra o mais importante item no custo de produção de cacau na Bahia até a década de 60 , é por meio dela que os produtores buscam reduzir custos, viabilizando a produção e tornando seu produto competitivo internacionalmente. Como não era possível reduzir a quantidade de mão-de-obra, uma vez que o aumento da produção implicava ocupação de maior área e maior número de trabalhadores (produção extensiva), reduzia-se o custo com mão-de-obra por meio de menores remunerações pagas aos trabalhadores rurais.

Apesar da diversidade e da complexidade nas relações de produção na economia cacaueira baiana, podem-se evidenciar três principais categorias de mão-de-obra que proporcionaram a redução do custo variável nessa produção: ${ }^{11}$ a) assalariado - também chamado de trabalhador, operário, diarista, peão. Pode ser permanente (morar na fazenda), ou temporário (os bóias-frias do cacau). Pode ser contratado pela diária, neste caso, ganha (de direito) um salário mínimo e trabalha (em termos legais) 8 horas diárias; ou pode ser contratado por empreitada. Assim, o trabalhador aceita fazer determinada tarefa por "x" (qualquer atividade inerente à produção de cacau), cada semana toma um adiantamento em dinheiro, geralmente correspondente ao valor pago ao assalariado, e deixa o saldo na mão do patrão para receber no final da empreitada; ${ }^{12}$ b) contratista - recebe uma terra por 3 a 6 anos para plantar cacau, utilizando-a também para agricultura de subsistência enquanto planta os cacaueiros. Quando devolve a terra recebe um percentual, anteriormente acertado, por pé de cacau plantado; c) burareiro - tem uma terra de 20 a 40 hectares titulada ${ }^{13}$ com plantio de cacau e de outros produtos, chega no máximo a 400 arrobas de cacau e mantém estreitas relações, geralmente de dependência, com o médio e grande produtor.

${ }^{11}$ Entendem-se como custo variável na produção de cacau na Bahia, numa perspectiva de produção extensiva, as despesas com pagamento da força de trabalho para as funções de formação, manutenção e exploração dos cacauais, aí compreendidas as atividades de colheita, transporte, secagem e ensacamento das amêndoas de cacau. (COX, 1966, p. 8).

12 Os contratos tanto da diária quanto das empreitadas são feitos verbalmente.

${ }^{13} \mathrm{Na}$ região, quando o burareiro não possui a titulação da terra denomina-se posseiro. 
No que diz respeito ao assalariado, predominaram, até a década de 60 , o assalariado permanente, chegando a $72 \%$ do total dos trabalhadores,${ }^{14}$ e o contrato pela diária. Esse tipo de assalariado e de contrato contribuía para a redução dos custos de produção. Contratar pela diária implicava (legalmente) uma remuneração ao trabalhador equivalente ao salário mínimo regional. Isso de fato não ocorria. Tecendo considerações sobre esse aspecto, Cox diz "...considerando o salário pago em algumas empresas, ele está abaixo da lei, em média, 30\%" (cox, 1966, p. 10). Segundo o Centro de Estudos e Ação Social (CEAS, 1985), a diária paga às mulheres é pouco mais da metade da diária paga aos homens e a diária paga às crianças seria ainda menor. Também as 8 horas diárias de trabalho (legal) não eram respeitadas, chegando alguns trabalhadores a trabalhar 10 horas por dia.

A falta de estradas entre as zonas produtoras (fazendas) e as cidades tornava difícil o deslocamento do trabalhador rural aos centros urbanos; isolado nas fazendas, o assalariado permanente passa a constituir consumidor "obrigatório" dos barracões. ${ }^{15}$ A regra observada era a seguinte: ao chegar à fazenda, o assalariado fazia a primeira compra, passando à condição de devedor antes mesmo de iniciar o trabalho. Os altos preços dos produtos e a desonestidade de alguns fazendeiros, acrescentando à conta (débito) produtos não efetivamente comprados, elevavam o débito do trabalhador constantemente, tornando-o "eterno" devedor do proprietário. Esse mecanismo fazia com que o trabalhador morasse por muitos anos em uma fazenda e que de lá saísse sem jamais ter recebido sua remuneração em espécie (moeda).

O contratista foi o principal agente na redução dos custos de implantação do produto cacau. Quando entregava a terra ao contratista, o fazendeiro eximia-se de quaisquer riscos ou perdas, cabendo-lhe apenas efetuar o pagamento por pé de cacau que "vingasse". Era por intermédio desse pagamento que se verificava a principal vantagem do dono da terra: os contratistas, geralmente descapitalizados, antecipavam parte do dinheiro que teriam direito ao final do contrato. Os juros praticados pelos proprietários da terra distanciavam-se dos juros de mercado, aumentando substancialmente a dívida, isso resultava em que, no final do contrato, o contratista nada mais tinha a receber e em alguns casos passando à condição de devedor para com o fazendeiro. Sendo os contratos celebrados verbalmente, era

${ }^{14}$ De acordo com pesquisa feita pelo Centro de Estudos e Ação Social (CEAS, 1985).

${ }^{15}$ Espécie de posto de venda de consumo pessoal rural de propriedade do fazendeiro no qual o trabalhador era obrigado a comprar. 
comum que, ao final deles, o proprietário reduzisse, unilateralmente, o valor anteriormente acertado por pé de cacau. ${ }^{16}$

A análise de como o burareiro viabilizou a redução dos custos de produção na média e grande propriedade pode ser evidenciada sobre três aspectos: a) por meio da produção de bens de consumo - estando o grande e o médio proprietários voltados exclusivamente para a produção de cacau, coube historicamente ao burareiro produzir os bens de salários como farinha de mandioca, banana, abóbora, milho, aves e ovos que chegavam direta ou indiretamente aos trabalhadores das grandes e médias fazendas; ${ }^{17} \mathrm{~b}$ ) como assalariados na grande e média propriedade - Navarro e Asmar ${ }^{18}$ constatam que em cada três burareiros, um tinha uma ocupação nas médias e grandes propriedades, isso sem considerar os outros membros da família. Importante também é a conclusão a que chega Baiardi a esse respeito:

Quanto ao assalariamento temporário do burareiro e de membros de sua família, a relação em essência em nada difere da que se estabelece entre o grande e o médio proprietário e o trabalhador assalariado, salvo no que se refere ao preço da diária (...) esse trabalho sempre tem uma remuneração abaixo do trabalho assalariado (BAIARDI, 1984, p. 98).

c) pela venda de amêndoas da produção burareira ao grande e médio proprietário. Essa venda pode ser realizada em dois estágios: o cacau mole, retirado da quebra do fruto diretamente para ser comercializado; o cacau fermentado ou seco com maior valor comercial. Os motivos que levam a essa venda antecipada (venda não realizada com os agentes exportadores) são: a inexistência de instalações de fermentação e secagem na propriedade do burareiro, isso no caso da venda de cacau mole e fermentado, mas essencialmente como entrega do produto por vendas antecipadas e/ou pagamento de empréstimos e até mesmo por fidelidade quando o comprador é seu vizinho. A CEPLAC estima que essa venda direta do burareiro para o fazendeiro é em média $50 \%$ abaixo do preço de mercado. ${ }^{19}$

16 Também não era incomum a bandidagem por parte dos proprietários das terras (fazendeiros) nesta relação. Eliminava-se o contratista (morte), expulsavam-se as viúvas e filhos, nada pagando pelos pés de cacau. CEAS (1985, p. 23).

17 Nesse sentido, as feiras de sábado exerceram importante papel, especialmente a partir de 1931 com a construção das estradas pelo ICB.

${ }^{18}$ Citados por BAIARDI (1984, p. 98).

${ }^{19}$ Todas as informações que tiverem como fonte a CEPLAC foram retiradas dos enformes técnicos e relatórios anuais da CEPLAC publicados entre 1965-1980. 


\section{DINAMIZAÇÃO E PROPAGAÇÃO DA BASE ECONÔMICA CACAU}

\section{Custo do produto de exportação}

A melhoria verificada na rede de transporte após a criação do ICB em 1931, que resolve um dos principais problemas da cacauicultura, aprimora-se a partir dos anos 60. Fatores como a construção da BR 101 no início da década de 70, cortando toda a região sul da Bahia, a reestruturação do porto de Ilhéus em 1971, agora com status de porto internacional, e a modernização das estradas das zonas produtoras para as cidades, e dessas para os principais centros urbanos regionais Ilhéus e Itabuna, constituem os principais pontos desse aprimoramento.

A grande transformação no custo de produção de cacau para exportação na Bahia, contudo, verifica-se no que diz respeito à produtividade. A forma de produzir cacau, até então baseada na terra e na mão-de-obra (produção extensiva), começa a mudar na década de 60 e consolida-se na década de 70. A organização do quadro pessoal efetivo, a criação do centro de pesquisa, do departamento de extensão rural e a fundação da escola técnica, respectivamente nos anos 1963, 1964 e 1965 consolidam a Ceplac como órgão que comanda a cacauicultura baiana, ${ }^{20}$ bem como possibilita a ela iniciar a produção de tecnologia própria e a transferência para a lavoura de modernas técnicas agrícolas.

$\mathrm{Na}$ "modernização conservadora" 21 da cacauicultura, a Ceplac utilizou dois tipos de inovação: a) inovação físico-química, que modifica as condições naturais do solo, elevando a produtividade do trabalho aplicado a esse meio de produção básico. A inovação físico-química para a plantação de cacau na Bahia se deu pelo denominado "pacote tecnológico da Ceplac" composto por: arboricidas, calcário, fungicida, inseticidas e adubos; b) inovação biológica, que é a introdução de novos cultivares, com produtos e distintas regiões, melhoria genética, controle de pragas e moléstias. Essa inovação afeta a velocidade de rotação do capital adiantado no processo produtivo por meio da redução do período de trabalho e da potencialização

${ }^{20}$ Apesar de criada em 1957, inicialmente a Ceplac teve um caráter emergencial.

${ }^{21}$ Cognominaram-se de modernização conservadora as transformações verificadas na agricultura brasileira a partir da década de 60 , decorrentes da mudança na base técnica de produção rural (industrialização) viabilizada por um sistema financeiro para esse fim, sem que houvesse qualquer mudança na propriedade territorial agrícola. 
das inovações físico-químicas. Com essa finalidade, criou-se na Bahia o Programa de Renovação dos Cacauais Decadentes.

Analisando os anos 1965-1980 (Tabela 1) observa-se que a produção de cacau, medida em toneladas, aumenta em 113,97\%; a área ocupada, medida em hectares, aumenta $37,83 \%$ e o rendimento (produtividade) passa de $375 \mathrm{Kg} / \mathrm{ha}$ para $733 \mathrm{Kg} / \mathrm{ha}$. Sendo assim, pode-se afirmar que o aumento na produção de cacau verificado no período deveu-se essencialmente ao aumento da produtividade, ou seja, resultou das inovações tecnológicas implementadas pela Ceplac, especialmente as inovações físico-químicas. Segundo Baiardi (1984), em 1960, apenas 74 estabelecimentos na região cacaueira baiana utilizavam fertilizantes e corretivos químicos. Esse número passa para 2.731, em 1970, e chega a 6.244 estabelecimentos em 1975.

As mudanças na forma de produzir cacau refletiram-se nos custos de produção. Menezes, ${ }^{22}$ pesquisando a produtividade e a taxa marginal de retorno de determinados fatores na produção de cacau, com 80 produtores com contabilidade agrícola controlada, chega à relação custo total/renda bruta de 60\%. Baiardi (1984), analisando o preço de custo de exploração do cacau, chega a uma relação custo total /preço de mercado também de $60 \%$. Verifica-se que esse valor de $60 \%$ é bem menor que o valor de $74 \%$ encontrado por Cox em 1966. Constata ainda Baiardi que o valor do custo de mão-deobra no custo variável é de $38,58 \%$, valor substancialmente inferior ao valor de $70,28 \%$ encontrado por Cox em 1966, e que o custo dos produtos químicos (fertilizantes, calcário, defensivos, combustíveis etc.), com uso inexistente na análise de Cox, representa agora $61,42 \%$ desse custo.

\section{Demanda pelo produto cacau}

Enquanto os principais países produtores de cacau sempre estiveram situados na África Ocidental e na América do Sul - Gana, Nigéria, Costa do Marfim, Brasil, Camarões - os principais países consumidores são os países europeus - Alemanha, Reino Unido, França, Itália - e os Estados Unidos que, juntos, respondiam por mais de $50 \%$ do consumo mundial de cacau no período de 1970-1974. Sendo também grandes consumidores, nesse período, a União Soviética e o Japão.

A produção mundial de amêndoas de cacau oscilou em torno de 1.400.000 toneladas por ano na década de 70. Sendo que, especificamente no ano de 1970, o valor total do comércio mundial de cacau aproximou-se de 1

${ }^{22}$ Citado por BAIARDI $(1984$, p. 81$)$. 
Bilhão de dólares. A maioria das transações comerciais envolvendo cacau é realizada pelas bolsas de Londres e Nova Iorque.

Constata-se que o índice de consumo per capta do produto do cacau é alto (Tabela 2) para o ano de 1974, sendo de 3,7Kg para a Suécia, de $3,1 \mathrm{Kg}$ para a Bélgica e de 2,6 Kg para a Holanda (principais consumidores), o que sugere uma demanda com alta elasticidade-renda.

Um outro aspecto positivo em relação à demanda de cacau brasileira é evidenciado por Macedo (1976) que, partindo do percentual da participação do Brasil no mercado internacional do cacau, da elasticidade da demanda mundial de cacau em termos de amêndoas e da elasticidade da oferta de amêndoas dos outros produtores, chega ao valor de menos seis ($6,00)$ para a elasticidade da demanda mundial de cacau de procedência brasileira. ${ }^{23}$

\section{A distribuição da renda regional}

Segundo os valores encontrados pelo Instituto Brasileiro de Geografia e Estatística (IBGE), calculados por meio do índice de Gini, ${ }^{24}$ a partir de 1950, a distribuição da renda no Brasil é uma das mais desiguais do mundo. O sociólogo Selem Asmar (1985), a partir de dados do diagnóstico socioeconômico para a região cacaueira da Bahia, feito pela Ceplac, analisa a distribuição de renda de Ilhéus e Itabuna para o ano de 1973. Em seguida, compara a distribuição de renda no Brasil em 1970, com a distribuição de renda verificada nas duas principais cidades da região cacaueira baiana, feita por ele para 1973 (Tabela 3). ${ }^{25} \mathrm{O}$ resultado surpreende, pois as duas principais cidades da região têm uma distribuição de renda pior do que a distribuição de renda do país. Numa correlação inversa entre a percentagem da população e a percentagem da renda nos diferentes módulos de $10 \%$ da população, os dados evidenciam que, em relação à distribuição de renda, a cidade de Itabuna é mais injusta que a cidade de Ilhéus. Os 10\% mais ricos de Itabuna concentram $52,99 \%$ da renda, contra $41,68 \%$ dos $10 \%$ mais ricos de

${ }^{23}$ Elasticidade da demanda excedente.

${ }^{24} \mathrm{O}$ índice de Gini define o grau de desigualdade de uma estrutura de distribuição de renda variando de $\geq 0$ a $\leq 1$. Quanto menor a desigualdade na estrutura da renda menor o valor encontrado e vice-versa.

${ }^{25}$ Como usual, o autor dividiu a população em dez decis, o que perfaz $100 \%$, construindo uma tabela em que, na parte superior, situam-se os $10 \%$ dos de maiores rendas, decrescendo até a parte inferior que termina com os $10 \%$ dos mais pobres ou de menores rendas. 
Ilhéus. Ainda segundo o estudo de Asmar, os 10\% mais pobres de Itabuna e Ilhéus concentram menos rendas do que seus equivalentes no Brasil.

Estudos da Ceplac ${ }^{26}$ indicam que os índices de concentração nos principais municípios da região cacaueira da Bahia estão acima de 0,52 , de acordo com o índice de Gini, e que a renda média das principais cidades regionais representava, em 1973, somente $81,37 \%$ do salário mínimo regional.

Para o sociólogo Adeum Sauer, a contradição básica na distribuição de renda regional localiza-se entre o valor substancial da renda gerada pelo cacau, em contrapartida com os poucos benefícios regionais em termos de indicadores de desenvolvimento social como infra-estrutura, educação, saúde, habitação, comunicação e outras necessidades, e acrescenta “... há uma histórica concentração de riqueza e de poder, além da mentalidade desta elite, culpada pela evasão da renda regional" (SAUER, 1982, p. 274).

\section{Diversificação regional}

Devido a mais de $95 \%$ da produção de cacau brasileira ter sua origem na Bahia, tornou-se a cacauicultura a atividade econômica predominante no sul do estado baiano. Esse fato implicou o não surgimento de qualquer outra atividade agrícola importante nessa região.

Apenas a produção de gado para corte e a produção de madeira e de bananas tiveram certo peso na região. A produção de gado de corte verificou-se por meio da pecuária extensiva, sendo o município de Itabuna, com 32.761 cabeças de gado e 31.596 hectares destinados à pecuária, o maior produtor. Também destacaram-se na produção de gado os municípios de Aurelino Leal e Belmonte, com 19.232 e 18.766 cabeças, respectivamente. No plantio de mandioca, Gandu, com 25.120 toneladas, e Wenceslau Guimarães, com 16.262 toneladas, aparecem como principais produtores. Observa-se, contudo, que a mandioca é produzida, mesmo que em pequenas quantidades, em todos os municípios da região.

$\mathrm{O}$ destaque entre os três produtos é a produção de bananas. Tal destaque deve-se ao fato de a banana fazer parte do processo de plantação do cacau (sombreamento para as mudas dos cacauais). Assim, contata-se a produção de banana em todos os municípios regionais. Fora esses três produtos, tudo o mais que se produziu na região foi em nível de experiência: abacaxi, cravo da índia, guaraná e dendê ou como agricultura de subsistência: arroz, feijão e milho.

${ }^{26}$ Citado por BAIARDI (1984, p. 144) 
A vocação histórica, por parte do homem regional, para plantar cacau, defendida pelos sociólogos regionais, e a facilidade em transformar o cacau em dinheiro, o que levou o cacau a ser denominado planta dos frutos de ouro, são apontadas como fatores determinantes da predominância na produção de cacau. Pretende-se não entrar no debate entre sociólogos e historiadores regionais sobre tal "vocação"; a verdade é que, mesmo após 20 anos de crise da cacauicultura baiana, os produtores insistem em plantar cacau, chegando alguns a dizer que não sabem desenvolver outra atividade produtiva. O segundo aspecto é mais evidente: criou-se na região cacaueira uma rede de comercialização, aprimorada a partir de 1931, facilitando a venda do produto cacau e sua transformação em espécie. Assim, o problema da comercialização é apontado pelos produtores como principal obstáculo à produção de outros produtos agrícolas.

\section{Encadeamento do produto cacau}

Em estudo comparativo das repercussões regionais e nacionais do cacau e do café, nos seus momentos de auge, ${ }^{27}$ as pesquisadoras Willumsem e Dutt (1991), utilizando técnicas de insumo-produto, analisam o efeito de encadeamento intersetorial para os dois produtos, encontrando os seguintes resultados: a) nos efeitos para trás (demanda de insumos de outros setores), os coeficientes técnicos apresentam-se similares para os dois produtos - a parcela de insumos materiais utilizada atinge 19\% para o cacau e $22 \%$ para o café, sendo a parcela restante o valor adicionado; b) nos efeitos para frente (como insumos para outros setores), os coeficientes técnicos do café mostram que sua produção total é alocada para a demanda intermediária, para processamento (limpeza, seleção etc.) - no caso do cacau, somente $37 \%$ da produção são utilizados como insumo em outros setores e a maior parte desse insumo é utilizada fora da região; c) no efeito da demanda final, ${ }^{28}$ (devido ao aumento da demanda causado por rendas mais altas), a distribuição da renda é similar nos dois casos - os coeficientes de mão-de-obra de 0,22 e 0,17 respectivamente para o cacau e o café, mostram que ambos os produtos são intensivos em mão-de-obra, utilizando-a de forma semelhante.

${ }^{27}$ Os momentos considerados são: final do século XIX e início do século XX para o café e as décadas de 60 e 70 para o cacau.

28 Pela impossibilidade (falta de dados) para construir um modelo multirregional de insumo, produto com demanda endógena desagregada em consumo de bens domésticos e importados, utilizou-se a distribuição do valor adicional agregado esclarecimento das autoras do estudo. 
As autoras chamam atenção para algumas características que esses números escondem: maior número de empregados e maior produtividade no setor café; menores salários no setor cacau, limitando o consumo e sua diversificação; e maior uso da poupança para especular e consumir (produtos importados) pelo cacauicultor. Concluem então, que, ressalvadas essa observações, os resultados encontrados para o cacau no sul da Bahia são, praticamente, similares aos encontrados para o café no sudoeste do Brasil, exceto no caso dos efeitos para frente.

\section{CONSIDERAÇÕES FINAIS}

Pode-se dizer, de acordo com as considerações efetuadas, que ao chegar à década de 60 , a região cacaueira da Bahia já teria consolidado sua base de exportação - o cacau, ou seja, colocava o produto no mercado a preços competitivos. Reduziu o custo de transporte por meio da construção de estradas, ligando os locais de produção aos locais de comercialização, e por meio da construção do porto de Ilhéus, reduzindo o custo para exportar cacau. A redução dos custos de produção verificou-se pelas relações de produção. $\mathrm{O}$ fato de prevalecerem na região relações de produção não capitalista e semicapitalista possibilitou uma baixa remuneração ao capital variável que, numa produção extensiva, como a verificada na região cacaueira da Bahia antes de 60 , constituía o principal item nos custos totais de produção.

Apesar de algumas transformações estruturais verificadas no período 1965-1980, como por exemplo, a criação da Ceplac, do Centro de Pesquisa do Cacau, a construção do porto de Ilhéus e de outros aspectos positivos para a dinamização, tais como: aumento médio nas quantidades produzidas de 157\%; aumento médio nas exportações de 50\%; aumento médio nos preços em dólares por toneladas de $118 \%$, o que evidencia, nesses dois últimos casos, o incremento da demanda externa, e aumento médio por hectares de até $95 \%$ no período de $1965-1980$, a dinamização do produto cacau não aconteceu. A grande desigualdade na distribuição de renda, a não diversificação regional e efeitos negativos para frente do encadeamento do produto cacau, aspectos fundamentais para a efetiva dinamização e sua conseqüente propagação apresentam resultados negativos. 


\title{
RESUMO
}

Este artigo objetiva analisar os efeitos das exportações de cacau para o crescimento e desenvolvimento da região cacaueira da Bahia no período de 1965-1980. Baseando-se nos elementos propostos por Schwartzman para uma estratégia de crescimento e desenvolvimento regional a partir de uma base de exportação, este artigo examinou três importantes aspectos relacionados a este produto primário: a) sua consolidação, na qual os principais fatores são os custos de produção: custos de transferências e custos de processamento; b) sua dinamização; e c) sua propagação. Além dos custos de produção, estes dois últimos itens levaram em consideração a demanda pelo produto cacau, a distribuição da renda regional, a diversificação e o encadeamento do produto cacau. Por fim, a conclusão a que se chegou foi que a região cacaueira da Bahia conseguiu consolidar sua base de exportação, mas não foi capaz de dinamizá-la e, conseqüentemente, o processo de desenvolvimento regional não foi efetivado no longo prazo.

Palavras-chave: base de exportação, crescimento regional, desenvolvimento regional, cacau, Bahia.

\begin{abstract}
This article aims at analysing the effects of cocoa exports for the growth and development of the cocoa region in Bahia during the 1965-1980 period. In this regard, this article, based on Schwartzman's proposition for a regional growth and development strategy from an export base, examines three important aspects related to this primary product: a) its consolidation, in which the main factors are the production, transfer and processing costs; b) its dynamism; and c) its propagation. These two last items take into consideration, in addition to the production costs, the demand for cocoa, the regional income distribution; the diversification as well as the linkages effects of cocoa. The article concludes that the cocoa region in Bahia succeeded in consolidating its export base, but it was not able to make it dynamic and consequently the regional development could not happen in the long term.

Key-words: export base, regional growth, regional development, cocoa, Bahia.
\end{abstract}




\section{REFERÊNCIAS}

ASMAR, Selem. Economia da microrregião cacaueira. Ilhéus, 1985.

BAIARDI, Amilcar. Subordinação do trabalho ao capital na lavoura cacaueira da Bahia. São Paulo/Salvador: Hucitec, 1984.

GARCEZ, Angelina, N. R.; FREITAS, F. G. Diagnóstico socioeconômico da região cacaueira da Bahia: história e economia social. Rio de Janeiro: Carta Gráfica, 1975.

CEAS. Caderno do Centro de Estudos e Ação Social, Salvador, n. 90, 1985.

CEPLAC. Informes técnicos e relatórios anuais. Ilhéus - BA: 1965-1980.

COX, Richard. Analisis Preliminar de Los Costos de Producción de Cacao en Bahia en el Años Agricola 1965/6. Ihéus: Ceplac, 1966.

. Instituto de Cacau da Bahia: meio século de história. Salvador: Secretaria de Agricultura do Estado da Bahia, 1981.

MACEDO, A. F. Avaliação social de custo-benefício da atividade de exportação de cacau na forma de produtos derivados. Salvador: Universidade Federal da Bahia, 1976.

NORTH, Douglas C. Teoria da localização e crescimento econômico regional. Economia regional: textos escolhidos. In: SCHWARTZMAN, J. (Org.). Belo Horizonte: Cedeplar/ Cetrade/Minter, 1977.

SAUER, Adeum. Estudos de avaliação da criação de emprego e fixação da mão-de-obra na cacauicultura brasileira pelo Procacau. Informe Técnico Ceplac, Ilhéus, 1982.

SCHWARTZMAN, J. A. A teoria da base de exportação e o desenvolvimento regional. In: HADDAD, P. R. Desequilibrios regionais e descentralização industrial. Rio de Janeiro: Ipea/Iplan, 1975.

TOSTA FILHO, Inácio. Comercialização do cacau e produtos derivados. Salvador: Miniográfica, 1960.

WILLUMSEN, Maria J.; DUTT, Amitava Krishna. Café, cacau e crescimento econômico. Revista de Economia Politica, v. 11, n. 3, jul./set. 1991.

\section{OUTRAS FONTES PESQUISADAS}

ASSOCIAÇÃO COMERCIAL DE ILHÉUS. Relatório Anual. Ilhéus, 1915.

BANCO CENTRAL DO BRASIL. Boletim. Brasília, jan. 1984.

CEPLAC. Boletins técnicos, relatórios anuais e outros documentos do período de 1965-1980.

CENTRO DE ESTUdOS E AÇÃO SOCIAL. Caderno do Centro de Estudos e Ação Social, Salvador, n. 90, 1985.

ENTREVISTAS CEDIDAS PARA A DISSERTAÇÃO, 2001.

JORNAL DA TARDE DE ILHÉUS. Edições de 26 e 28 jun. 1967.

ICB. Relatórios Anuais 1931 a 1941. 
MARINHO, P. L. Exportação de cacau, crescimento e desenvolvimento...

Tabela 1 - ÁREA OCUPADA, EM PRODUÇÃO E RENTABILIDADE

\begin{tabular}{lccccc}
\hline \multicolumn{1}{c}{ ÁREAS EM HECTARES } & & & \\
\hline ANOS & $\begin{array}{c}\text { ÁREA } \\
\text { OCUPADA }\end{array}$ & PRODUÇ̃̃o & PLANTIO & $\begin{array}{c}\text { PRODUČñ } \\
\text { EM TONELADAS }\end{array}$ & $\begin{array}{c}\text { RENDIMEN] } \\
\text { Kg /ha }\end{array}$ \\
\hline 1965 & 400.000 & 400.000 & $\mathrm{x}$ & 150.126 & 375 \\
\hline 1966 & 400.150 & 400.00 & 150 & 161.164 & 403 \\
\hline 1967 & 402.241 & 399.985 & 2.091 & 159.732 & 399 \\
\hline 1968 & 403.259 & 399.690 & 1.018 & 106.068 & 265 \\
\hline 1969 & 404.092 & 399.197 & 833 & 197.000 & 493 \\
\hline 1970 & 405.621 & 398.564 & 1.529 & 158.000 & 396 \\
\hline 1971 & 408.369 & 398.043 & 2.748 & 207.000 & 420 \\
\hline 1972 & 412.647 & 400.476 & 4.278 & 173.000 & 461 \\
\hline 1973 & 419.968 & 401.301 & 7.321 & 185.000 & 496 \\
\hline 1974 & 432.022 & 401.334 & 12.054 & 198.995 & 684 \\
\hline 1975 & 444.955 & 402.007 & 12.933 & 274.998 & 551 \\
\hline 1976 & 457.687 & 404.860 & 12.732 & 222.996 & 602 \\
\hline 1977 & 473.794 & 410.182 & 16.107 & 246.995 & 654 \\
\hline 1978 & 495.508 & 417.688 & 21.714 & 273.000 & 756 \\
\hline 1979 & 519.234 & 427.617 & 23.726 & 323.275 & 733 \\
\hline 1980 & 551.325 & 438.113 & 32.091 & 321.227 & \\
\hline
\end{tabular}

FONTE: Ceplac 1965-1980.

Foi considerado o ano civil brasileiro

Tabela 2 - CONSUMO PER CAPITA DE PRODUTOS DE CACAU (PRINCIPAIS CONSUMIDORES 1974)

\begin{tabular}{ll}
\hline PAÍSES & Kg \\
\hline SUÍCA & 3,7 \\
BELLGICA & 3,1 \\
HOLANDA & 2,6 \\
ALEMANHA & 2,4 \\
REINO UNIDO & 2,2 \\
DINAMARCA & 1,8 \\
CANADÁ & 1,7 \\
FRANÇA & 1,7 \\
EUA & 1,6 \\
SUÉCIA & 1,6 \\
\hline
\end{tabular}

FONTE: Macedo (1976, p. 10). 
MARINHO, P. L. Exportação de cacau, crescimento e desenvolvimento...

Tabela 3 - DISTRIBUIÇÃO DE RENDA, BRASIL (1970) E REGIÃO CACAUEIRA (1973)

\begin{tabular}{lccc}
\hline \multirow{2}{*}{ POPULAÇÃO (\%) } & \multicolumn{3}{c}{ RENDA (\%) } \\
\cline { 2 - 4 } & BRASIL & ITABUNA & ILHÉUS \\
\hline $10+$ & 46,47 & 52,49 & 41,68 \\
10 & 15,15 & 16,99 & 16,59 \\
10 & 9,95 & 9,89 & 11,26 \\
10 & 7,21 & 5,89 & 8,54 \\
10 & 6,17 & 4,35 & 6,38 \\
10 & 5.02 & 3,47 & 5,05 \\
10 & 3,81 & 2,63 & 3,88 \\
10 & 3,00 & 2,10 & 3,31 \\
10 & 2,05 & 1,49 & 2,29 \\
$10-$ & 1,16 & 0,70 & 1,02 \\
100,00 & 100,00 & 100,00 & 100,00 \\
\hline
\end{tabular}

FONTE: Asmar(1985, p. 37). 